\title{
Preparation and Properties of Agricultural Residuals-Iron Concentrate Pellets
}

\author{
Zhulin Liu, ${ }^{1}$ Xuegong Bi, ${ }^{2}$ Zeping Gao, ${ }^{1}$ and Yayu Wang ${ }^{2}$ \\ ${ }^{1}$ School of Metallurgical and Materials Engineering, Hunan University of Technology, Zhuzhou, Hunan 412007, China \\ ${ }^{2}$ State Key Laboratory for Refractory Materials and Metallurgy, Wuhan University of Science and Technology, Wuhan, \\ Hubei 430081, China \\ Correspondence should be addressed to Xuegong Bi; 1575595611@qq.com
}

Received 22 May 2017; Accepted 18 September 2017; Published 22 October 2017

Academic Editor: Merrick Mahoney

Copyright (c) 2017 Zhulin Liu et al. This is an open access article distributed under the Creative Commons Attribution License, which permits unrestricted use, distribution, and reproduction in any medium, provided the original work is properly cited.

In this paper, carbon-containing pellets were prepared by using crop-derived charcoal made from agricultural residuals and iron ore concentrates, and their pelletizing performance and properties were studied. Experimental results showed that the strengths of pellets were related to the particle size of concentrates and the content of moisture, bentonite, and crop-derived charcoal fines in the pelletizing mixture and the temperature of roasting and reduction. That the granularity of raw materials was fine and the bentonite content increased was beneficial to the improvement of pellet strengths. The suitable molar ratio of carbon to oxygen was 1.0 and the proper proportioning ratios of moisture and binder were $8.0 \%$ and $6.5 \%$, respectively. The pellet strengths increased accordingly with increasing the reduction temperature, and when the temperature reached $1200^{\circ} \mathrm{C}$, accompanied by the fast reduction of iron and the formation of crystal stock, the dropping strength of product pellets was 15 times and the compressive strength was $1650 \mathrm{~N}$; this may be improved by grinding of the concentrate, leading to acceptable strength for the blast furnace.

\section{Introduction}

The sustainable development of the steel industry is severely restricted by natural resources, energy supply capacity, and the earth environmental bearing capacity [1]. Crops are artificial plants and grow and develop by absorbing $\mathrm{CO}_{2}$ in the atmosphere and utilizing solar energy. Therefore, crops waste not only is a renewable energy, but also could not additionally increase $\mathrm{CO}_{2}$ in the atmosphere during combustion; it is completely carbon neutral, that is, has a feature of zero $\mathrm{CO}_{2}$ emission [2].

Further, because the ash generated by biomass combustion appears to be alkaline, it is possible to restrain the formation of contaminants such as $\mathrm{SO}_{2}, \mathrm{NO}_{x}$, and so on [3]. Moreover, burning in the open air of a large number of surplus crop straw will produce a great deal of gases and aerosol components. This will not only lead to a great waste of resources and destroy soil fertility, but also bring about serious air pollution [4]. Therefore, the application of crop wastes will improve the ecological environment. China owns extremely abundant biomass resources; the output of residues from forests and agricultural industry is 2 billion 29 million tons per annum. There mainly are crops straw, forestry residues, livestock manures, and energy crops [5]. The carbon content in wheat and corn straws is about $40 \%$ while that in rice husk accounts for $43 \%$ [6].

The product of crop wastes carbonization is essentially the same with charcoal in respect to chemical composition, being based on carbon and also having hydrogen, oxygen, nitrogen, and a few other elements, but very low ash and sulphur. Therefore, it is feasible to reduce iron ores with crop wastes $[7,8]$. More importantly, to substitute agricultural and forestry biomass charcoal for coal for producing carbonbearing pellets can not only realize the reuse of wastes and protect the environment, but also save coal and mitigate $\mathrm{CO}_{2}$ emission [9].

Babich et al. [10] studied charcoal behavior by its injection into the modern blast furnace. Specific surface area was measured with BET technique and the results showed that specific surface area of charcoals $\left(150 \sim 350 \mathrm{~m}^{2} / \mathrm{g}\right)$ is $60 \sim 350$ times greater than that for PC $\left(1.0 \sim 2.6 \mathrm{~m}^{2} / \mathrm{g}\right)$. This result is coincident with the higher reactivity that was determined 
TABLE 1: Chemical composition of concentrate.

\begin{tabular}{lccccccccccc}
\hline Component & $\mathrm{T} . \mathrm{Fe}$ & $\mathrm{S}$ & $\mathrm{P}$ & $\mathrm{SiO}_{2}$ & $\mathrm{FeO}$ & $\mathrm{Al}_{2} \mathrm{O}_{3}$ & $\mathrm{CaO}$ & $\mathrm{MgO}$ & $\mathrm{MnO}$ & $\mathrm{H}_{2} \mathrm{O}$ & $\mathrm{I} . \mathrm{L}$. \\
\hline Mass$\%$ & 60.67 & 0.11 & 0.05 & 12.00 & 9.23 & 1.07 & 0.50 & 1.00 & 0.33 & 10.96 & -1.30 \\
\hline
\end{tabular}

Note. I.L. is ignition loss.

by the Simultaneous Thermal Analysis (Netzsch, STA 409) method, the pilot injection plant test, and the coke bed simulator experiment. Pore characteristics were quantified by optical microscope with Soft Imaging Analysis. The overall porosity varies between $1 / 3$ and $1 / 2$ among the charcoal samples, but for PC no pores were identified. Although there are so far few measured data of porosity, surface area and reactivity for crop-derived charcoal were reported; it can be reasonably presumed that crop-derived charcoal is also superior to PC in terms of these three qualities.

Mathieson et al. [11] analyzed the potential for biomassderived charcoal to reduce net greenhouse gas emissions from the Australian steel industry and proposed many applications such as sintering solid fuel, cokemaking blend component, $\mathrm{BF}$ tuyere fuel injectant, $\mathrm{BF}$ nut coke replacement, BF carbon/ore composites of BOF prereduced feed, and steelmaking recarburiser. Actually, as early as in the 1980s, aiming at the application of abundant tropical forest resources in Brazil, Martins et al. [12] made a preliminary study on sponge iron production by using green pellets made of iron ores and charcoal mix. The binders used in their research consisted of water glass, lime, and cement. Hayashi and Iguchi [13] studied the possibility of partly substituting cedar flour for coal to produce carbon composite iron ore hot briquettes. Nakano et al. [14] have proposed that unreduced carbonore composite pellets or briquettes be added as blast furnace feed and manufactured nonspherical carbon composite in lab-scale. In their study on charcoal composite iron oxide pellets, Konishi et al. [15] derived charcoal from Japanese cypress and mixed it into $\mathrm{Fe}_{2} \mathrm{O}_{3}$ agent of $98 \%$ purity pellets at a ratio of $1 / 4$ with an addition of 3 mass $\%$ bentonite. And then pellets of about $10 \mathrm{~mm}$ in diameter were manually made and reduced at 1273,1373 , and $1473 \mathrm{~K}$ in $\mathrm{N}_{2}$ gas atmosphere. More recently, Li et al. [16] added straw fiber (without carbonization) to substitute for coal into South African iron ore for the preparation of metallized pellets. Pellets sized $22 * 10 \mathrm{~mm}$ were produced under $20 \mathrm{MPa}$ pressure without heating and binder addition. It was demonstrated that the strength of green pellets met the requirement of Rotary Hearth Furnace process. It is noted that there are few reports in the literature so far on the preparation and properties of crop-derived charcoal containing iron ore pellets.

In this work, feasibility of preparation of carbon composite iron ore pellets by using crop-derived charcoal was assessed and appropriate technological conditions were experimentally determined.

\section{Test Materials and Methods}

2.1. Chemical and Size Compositions of Concentrate. The raw materials for pellets preparation were concentrates provided by Hualing Xiangtan Iron and Steel Corporation (Group); the chemical composition is shown in Table 1. The reducing
TABLE 2: Approximate analysis of crop-derived charcoal.

\begin{tabular}{lccccc}
\hline Component & $\mathrm{A}_{\mathrm{d}}$ & $\mathrm{V}_{\mathrm{d}}$ & $\mathrm{FC}_{\mathrm{d}}$ & $\mathrm{S}_{\mathrm{t}, \mathrm{d}}$ & $\mathrm{M}_{\mathrm{ad}}$ \\
\hline Mass\% & 3.48 & 32.10 & 61.82 & 0.05 & 2.60 \\
\hline
\end{tabular}

Note. $\mathrm{A}_{\mathrm{d}}$ is ash content; $\mathrm{V}_{\mathrm{d}}$ is volatile content; $\mathrm{FC}_{\mathrm{d}}$ is fixed carbon content; $\mathrm{S}_{\mathrm{t}, \mathrm{d}}$ is total sulfur content; $\mathrm{M}_{\mathrm{ad}}$ is moisture content.

TABLE 3: Chemical composition of bentonite.

\begin{tabular}{lccccccc}
\hline Component & $\mathrm{Al}_{2} \mathrm{O}_{3}$ & $\mathrm{CaO}$ & $\mathrm{MgO}$ & $\mathrm{SiO}_{2}$ & $\mathrm{~K}_{2} \mathrm{O}$ & $\mathrm{Na}_{2} \mathrm{O}$ & I.L. \\
\hline Mass\% & 12.65 & 1.02 & 4.19 & 53.25 & 0.43 & 0.30 & 14.39 \\
\hline
\end{tabular}

agent was self-made crop-derived charcoal; the composition is shown in Table 2. The binder used was bentonite; the composition is shown in Table 3.

The crop-derive charcoal was prepared from rice husk and peanut shell through crushing, molding, and low temperature carbonization $\left(300 \sim 350^{\circ} \mathrm{C}\right)$ for the purpose of including more residual volatile matter.

The cumulative size distribution curve of concentrate is shown in Figure 1.

As can be seen from Figure 1, the size of this concentrate was a little too coarse for pelletizing ores; the cumulative percentage of minus $0.04 \mathrm{~mm}$ approximately accounted for $30 \%$ and that of minus $0.074 \mathrm{~mm}$ approximately accounted for only $80 \%$. As can be seen from Table 2 , the fixed carbon content in the self-made crop-derived charcoal was relatively low at only $61.82 \%$ while the volatile content was as high as $32.10 \%$. The reason is that the blocks made of crop wastes were relatively large, the carbonization temperature was lower, and the time was shorter, resulting in an insufficient carbonization. However, the ash content of biochar was only $3.48 \%$, which is favorable to the reduction of flux consumption and to the smelting of low Si content pig iron [17]. As can been seen in Table 3 that the $\mathrm{MgO}$ content in bentonite was relatively high, it belongs to Ca-based bentonite with a poorer bonding capacity.

2.2. Test Method. In the experiment, a vacuum heating furnace was used for carbonizing the collected crop wastes such as peanut hull and rice husk. After carbonization, they were crushed and ground. The concentrate and self-made crop-derived charcoal fines were, respectively, screened with 150,180 , and 200 mesh sieves; the obtained materials of corresponding sizes were used for pelletizing. The diameter of green balls was $8 \sim 12 \mathrm{~mm}$. In the tests, the water content of green balls was designated as $7.5 \%, 8.0 \%$, and $8.5 \%$. By taking into account the fact that the addition of crop-derived charcoal fines will decrease the strength of green balls, bentonite proportioning ratio was set as $6 \%, 6.5 \%$, and $7 \%$. According to investigation results of other researchers $[18,19]$, the molar ratio of carbon to oxygen $(\mathrm{C} / \mathrm{O}$ ratio) usually is 
TABLE 4: Material ratios of carbon-bearing pellets, mass $\%$.

\begin{tabular}{|c|c|c|c|c|c|c|}
\hline Test number & $\begin{array}{c}\text { Size of concentrate and } \\
\text { char/mesh }\end{array}$ & $\begin{array}{c}\mathrm{C} / \mathrm{O} \\
- \\
\end{array}$ & Concentrate & $\begin{array}{c}\text { Crop-derived } \\
\text { charcoal }\end{array}$ & Binder & $\mathrm{H}_{2} \mathrm{O}$ \\
\hline 1 & 200 & 0.9 & 67.9 & 18.6 & 6.0 & 7.5 \\
\hline 2 & 200 & 1.0 & 65.6 & 19.9 & 6.5 & 8.0 \\
\hline 3 & 200 & 1.1 & 63.4 & 21.1 & 7.0 & 8.5 \\
\hline 4 & 180 & 0.9 & 66.8 & 18.2 & 6.5 & 8.5 \\
\hline 5 & 180 & 1.0 & 65.6 & 19.9 & 7.0 & 7.5 \\
\hline 6 & 180 & 1.1 & 64.5 & 21.5 & 6.0 & 8.0 \\
\hline 7 & 150 & 0.9 & 66.8 & 18.2 & 7.0 & 8.0 \\
\hline 8 & 150 & 1.0 & 65.6 & 19.9 & 6.0 & 8.5 \\
\hline 9 & 150 & 1.1 & 64.5 & 21.5 & 6.5 & 7.5 \\
\hline
\end{tabular}

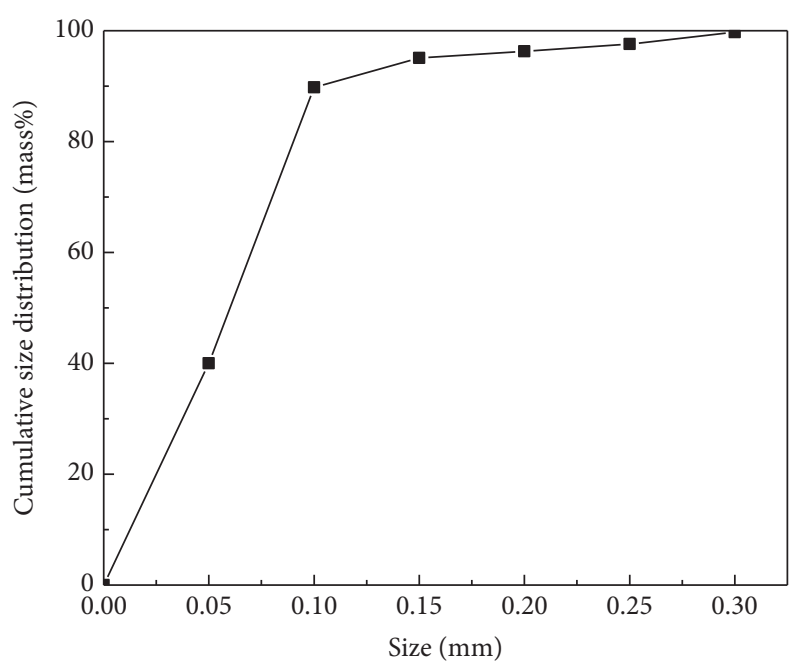

FIgURE 1: Cumulative size distribution of concentrate. around one. In this experiment, $\mathrm{C} / \mathrm{O}$ ratio was assigned as 0.9 , 1.0, and 1.1; the corresponding material ratios calculated are seen in Table 4 . The measurements of pelletizing performance mainly included the compressive strength, dropping strength, and shock temperature of green balls.

Measurement of the dropping strength of green balls: in each test, ten green balls of $10 \sim 12 \mathrm{~mm}$ in diameter are selected at pleasure and dropped onto a steel sheet of $10 \mathrm{~mm}$ in thickness, the height of dropping is $500 \mathrm{~mm}$, and the mean value of the number of dropping where there appeared flaws in any green ball or it broke into pieces is taken as the dropping strength of green balls in this test.

Measurement of the compressive strength of green balls: in each test, ten green balls of $10 \sim 12 \mathrm{~mm}$ in diameter are picked at random, they are pressed vertically at a compression speed not exceeding $10 \mathrm{~mm} / \mathrm{min}$, and the mean value of the exerted loads where flaws appeared in any green ball is taken as the compressive strength of green balls in this test.

Measurement of the shock temperature of green balls: in each test, ten green balls of $10 \sim 12 \mathrm{~mm}$ in diameter were selected at random, and, in the tubular furnace with a 320

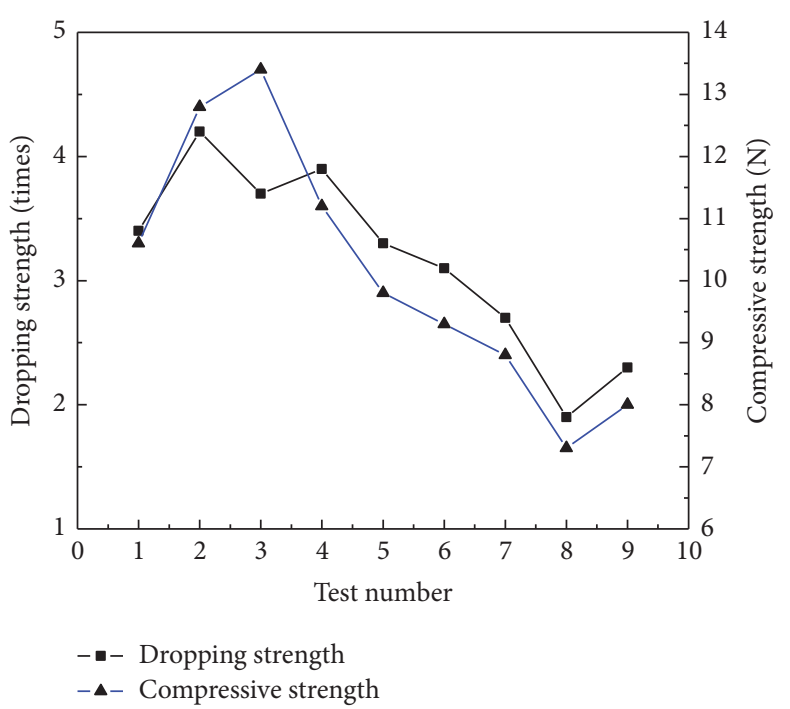

FIGURE 2: The dropping strength and compressive strength of green balls.

to $520^{\circ} \mathrm{C}$ temperature range, the temperature where the percentage of green balls that generated flaws inside achieves $10 \%$ is measured and taken as the shock temperature of green balls.

\section{Test Results and Analysis}

3.1. Properties and Their Analysis of Carbon-Containing Green Balls. After the disc pelletizer started running, the pelletizing mixture accounting for about one-third of the total weight of green balls was firstly added and water was dropped with a bottle onto the materials to form seed balls. The size of seed balls was controlled at around $2 \mathrm{~mm}$, and it was also required that the grain size was uniform. After seed balls formed, mist water was sprayed while materials were added according to the situation of balls growing. When most green balls grew up to $8 \sim 12 \mathrm{~mm}$ in diameter, it was stopped to add materials into the disc pelletizer and the pelletizer continued running for 3 5 min. The green balls properties of nine tests are shown in Figures 2 and 3. 


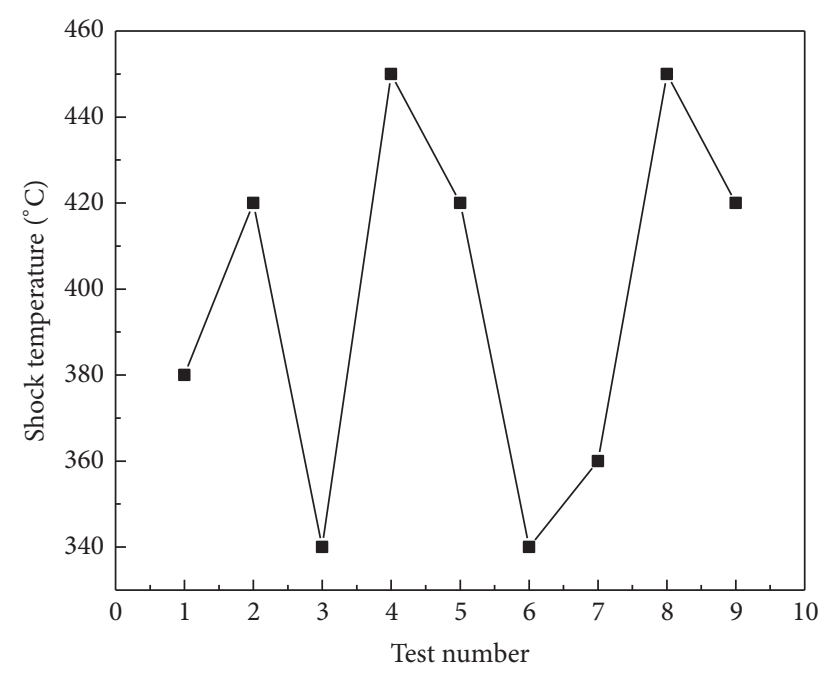

Figure 3: The shock temperature of green balls.

As can be seen from Figures 2 and 3, the quality of green balls dropping strength of test number 2 and the quality of green balls compressive strength of test number 3 were the best, respectively, achieving 4.3 times the dropping strength and $13.4 \mathrm{~N}$ compressive strength. However, the green balls shock temperature of test number 3 was only $340^{\circ} \mathrm{C}$, unfavorable to the high temperature reduction and calcination of pellets.

Making a comprehensive comparison, the overall property of test number 2 was the best: the dropping and compressive strengths were 4.2 times and $12.8 \mathrm{~N}$, respectively, and the shock temperature could reach $420^{\circ} \mathrm{C}$. The size of raw materials of test number 2 was 200 mesh, $\mathrm{C} / \mathrm{O}$ ratio was 1.0 , binder blending ratio was $6.5 \%$, and $\mathrm{H}_{2} \mathrm{O}$ content was $8 \%$.

The size of raw materials of the first three tests was smaller and accordingly the dropping strength and compressive strength were higher. The finer the raw materials size, the higher the surface free energy and, after water addition for lubrication, the smaller the diameter of the capillaries generated. The greater the capillary force, the stronger the binding force, and thus the dropping strength as well as the compressive strengths would increase.

Generally speaking, the dropping and compressive strengths of green balls increase with increasing the content of bentonite binder. The supper fine particles in bentonite and concentrate form gelatinous substance, and this kind of colloids fills up among iron ore particles, playing a good role of adhesive bridges. In addition, after absorbing moister, bentonite forms a colloid, which has a gelatinous structure of a "card room" type 3D network form. This gelatinous structure could improve the viscous resistance and shear strength of binding bridges, and thus increase the dropping strength, compressive strength, and shock temperature.

Why the shock temperature of test number 3 appeared abnormal is probably because $\mathrm{C} / \mathrm{O}$ ratio was higher and cropderived charcoal contained more volatile matters; thus the volatilization of volatile matters would be the primary cause that leads to green balls bursting and decreases the shock

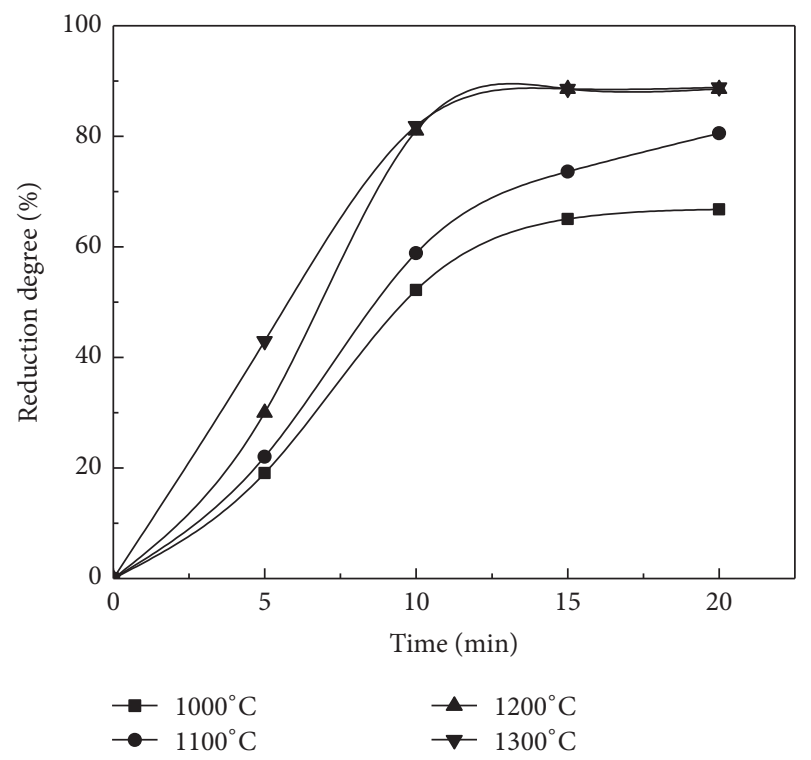

FIgURE 4: Reduction degree of carbon-bearing pellets versus time.

temperature. Similarly, due to the higher $\mathrm{C} / \mathrm{O}$ ratios, the shock temperature of tests number 6 and number 9 were decreased in different extents, but number 9 is actually still quite strong.

3.2. Metallized Pellets Properties and Analysis. For studying the effect of temperature on the reduction property of pellets, after drying at $110^{\circ} \mathrm{C}$, the green balls with $1.0 \mathrm{C} / \mathrm{O}$ ratio of test number 2 were isothermally autoreduced for $5,10,15$, and $20 \mathrm{~min}$, respectively, at various temperatures and under the condition of nitrogen protection.

In the weight loss of carbon-containing pellets, apart from oxygen loss, the carbon loss, the amount of volatile matters separated, and remaining water vaporized are also included. In this paper, the modified weight loss approach was utilized, that is, by taking carbon-containing alumina balls as a reference, to indirectly measure the separation ratio of volatile matters and water and to evaluate the degree of reduction with (1), which originated from a reference and was modified in this work.

$$
R=\frac{4}{7 M_{\mathrm{O}}}\left(f_{\Sigma}-f_{\mathrm{A}-\mathrm{P}}\right) W \times 100, \%,
$$

where $M_{\mathrm{O}}$ is oxygen amount in iron oxides, $\mathrm{g} ; f_{\Sigma}$ is the percentage of total weight loss, $\% ; f_{\mathrm{A}-\mathrm{P}}$ is the percentage of weight loss of volatile matters and moisture in carboncontaining alumina balls, \%; $W$ is the weight of carboncontaining pellets, g.

The maximum weight loss rate and the reduction degree at $20 \mathrm{~min}$ were obtained as shown in Table 5. The plots of reduction degree against time are described in Figure 4.

It can be seen from Table 5 and Figure 4 that, for carbon-bearing pellets, the maximum reduction degree and the maximum weight loss rate at $1200^{\circ} \mathrm{C}$ and $1300^{\circ} \mathrm{C}$ are all essentially identical. This is presumably because the porosity of crop-derived charcoal fines is relatively large, having bigger 
TABLE 5: Results of carbon-bearing pellets reduction at different temperatures.

\begin{tabular}{lcr}
\hline Temperature, ${ }^{\circ} \mathrm{C}$ & Weight loss rate at 20 min, $\%$ & Reduction degree at 20 min, $\%$ \\
\hline 1000 & 27.36 & 66.76 \\
1100 & 32.21 & 80.56 \\
1200 & 34.79 & 88.66 \\
1300 & 34.86 & 88.85 \\
\hline
\end{tabular}

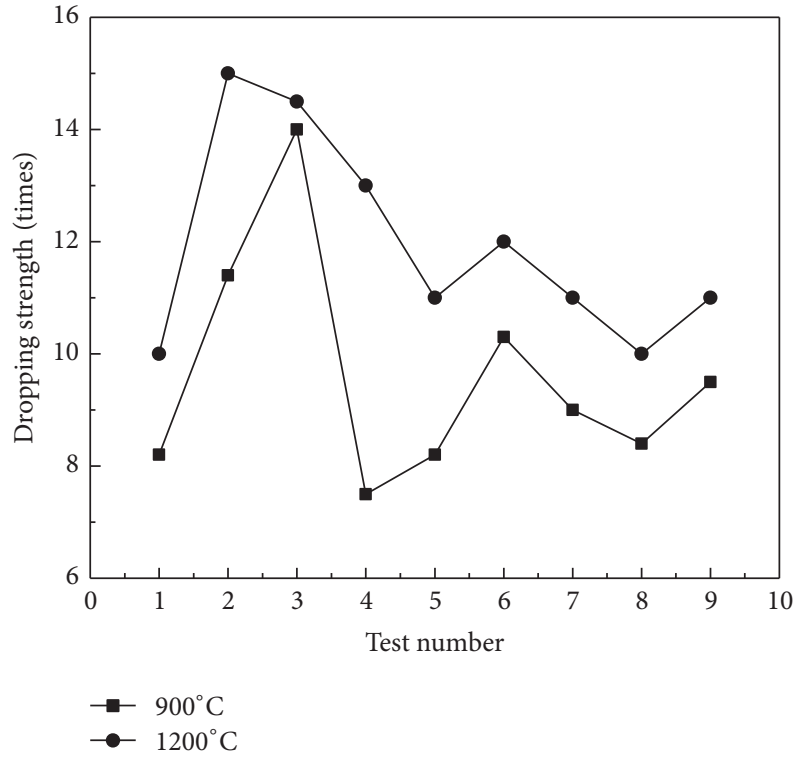

Figure 5: The dropping strength of pellets after reduction.

areas of reaction and also possessing higher degree of $\mathrm{CO}_{2}$ reaction compared to $\mathrm{PC}$; see Section 1, and with the addition of reduction by the $\mathrm{CO}$ and $\mathrm{H}_{2}$ in abundant volatile matters, the reduction process could rapidly proceed at only $1200^{\circ} \mathrm{C}$. Over $1200^{\circ} \mathrm{C}$, however, further increasing temperature had no great raising effect on the reduction extent of pellets. It is true that the reduction degree of pellets increased with temperature increasing, but, from the economic point of view, the appropriate reduction temperature of these carboncontaining pellets would be $1200^{\circ} \mathrm{C}$, with a reduction time of $15 \mathrm{~min}$.

Green balls of the above-mentioned nine tests were treated isothermally at $900^{\circ} \mathrm{C}$ for $20 \mathrm{~min}$; at this moment, direct reduction had not taken place in quantity in the pellets, and dropping and compressive strengths were measured. Again, the green balls were isothermally treated at $1200^{\circ} \mathrm{C}$ for $20 \mathrm{~min}$, metallized pellets were obtained by reduction, and dropping strength and compressive strength were measured and shown in Figures 5 and 6, respectively.

It can be seen from Figures 5 and 6 that, under the condition of $1200^{\circ} \mathrm{C}$, the dropping and compressive strengths of metallized pellets of each test are all higher than the pellets of their corresponding tests which were obtained under the condition of $900^{\circ} \mathrm{C}$ reduction temperature and had lower extents of direct reduction. The highest dropping strength and compressive strength of pellets reduced at $1200^{\circ} \mathrm{C}$ were 15 times and $1900 \mathrm{~N}$. The best was the pellets of test number

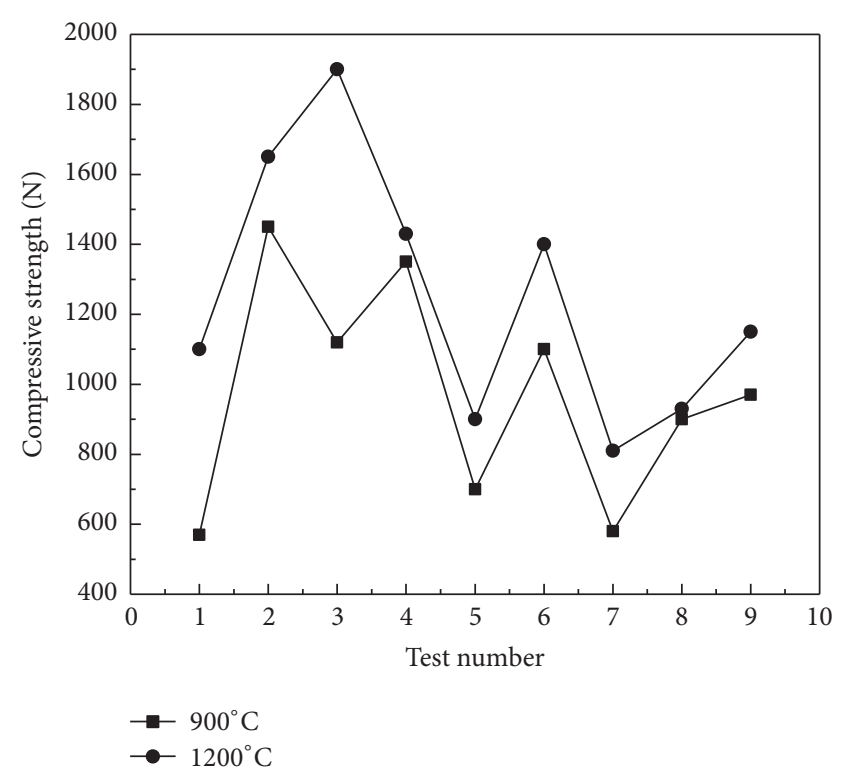

FIGURE 6: The compressive strength of pellets after reduction.

2 in respect to comprehensive properties; their dropping strength and compressive strength were 15 times and $1650 \mathrm{~N}$, respectively.

Reduction temperature has a positive impact on increasing the postreduction strength of pellets, and thus a lower temperature will bring about various physicochemical reactions proceeded slowly; above all, for carbon-containing pellets that give priority to the direct reduction, it is hard to achieve the consolidation effect. As temperature increases and the direct reduction reaction proceeds, more metallic iron forms and the metallic iron sinters increasing pellet strength.

3.3. Consideration of How to Decrease the Blending Ratio of Bentonite. As shown in Table 4, the blending ratio of bentonite in this work was rather high, ranging from 6.0 to 7.5 mass\%, which will bring about a higher production cost of pellets and a lower iron grade of pellets, meaning a higher slag volume and a greater fuel consumption of the blast furnace. The main reason why so much bentonite has to be proportioned into the pelletizing mixture is, in comparison with pulverized coal, crop-derived charcoal is poor in hydrophilia and ballability. The secondary cause is the blending ratio of charcoal being necessarily higher for a given $\mathrm{C} / \mathrm{O}$ ratio, due to its lower carbon content and its lower density. As a consequence, the bulk density of pelletizing 
mixture is smaller and the voidage between material particles is larger; thus more binder has to be blended.

There are some potential countermeasures [20] to solve this problem, including reducing the concentrate size to 325 mesh with use of the technique of wet-grinding or highpressure roller grinding, applying alkali-based bentonite of higher efficiency, and partly blending organic binders. This is the subject of future work.

\section{Conclusions}

(1) Under the condition that pelletizing time and pelletizer parameters are constant, the properties of carbon-containing pellets are related to the particle size of pelletizing materials, the content of moisture, the amount of bentonite blended, the amount of cropderived charcoal fines addition, and the temperature of reduction. The finer the raw materials particle size and the higher the binder content, the better the comprehensive performance of pelletizing. The water content needs to be appropriate. Too high a $\mathrm{C} / \mathrm{O}$ ratio could cause a decrease of the shock temperature of green balls.

(2) Under the condition that the particle size of concentrate and crop-derived charcoal fines were both 200 mesh, $\mathrm{C} / \mathrm{O}$ ratio was 1.0 , the bentonite content was $6.5 \%$, and water content was $8 \%$, the quality of green balls was better: the dropping strength reached 4.2 times, the compressive strength was $12.8 \mathrm{~N}$, and the shock temperature was $420^{\circ} \mathrm{C}$.

(3) The reduction process of crop-derived charcoal composite iron ore pellet could quickly be conducted at only $1200^{\circ} \mathrm{C}$; a $15 \mathrm{~min}$ holding time of high temperature was suitable.

(4) The dropping strength and the compressive strength of metallized pellets obtained by high temperature reduction at $1200^{\circ} \mathrm{C}$ were all higher than the pellets with lower direct reduction extents that were obtained under the reduction condition of $900^{\circ} \mathrm{C}$. The main reason was that the rapid reduction of metallic irons and the formation of a crystal stock between them significantly improved the mechanical strength of pellets. The dropping strength and compressive strength of pellets of test number 2 with a good comprehensive performance were, respectively, 15 times and $1650 \mathrm{~N}$, basically meeting the requirements of blast furnace feed materials in terms of strength.

Blast furnace pellets should have an average compression strength of $2500 \mathrm{~N}$. Future work should try to increase this strength.

\section{Conflicts of Interest}

The authors declare that there are no conflicts of interest regarding the publication of this paper.

\section{Acknowledgments}

Thanks are due to Hunan Province (A research project supported by the Hunan Province Science and Technology Program Foundation Grant no. 2012FJ3037).

\section{References}

[1] Z.-L. Liu, X.-G. Bi, and S.-Z. Shi, "Development of ecological blast furnace in 21st century," Kang T'ieh/Iron and Steel (Peking), vol. 43, no. 7, pp. 1-6, 2008.

[2] Y.-K. Liu, Q.-F. Sun, D.-M. Li, and Zh.-Q. Chen, "Current status and prospect of the utillization of biomass wastes," Chemical Engineer, no. 3, pp. 28-30, 2011.

[3] S. V. Loo and J. Koppejan, Handbook of Biomass Combustion and Co-firing, Twente University Press, Netherlands, 2002.

[4] M.-L. Li, J. Gu, H. Gao, Q.-J. Qin, and M.-J. Liu, "Preparing and application of bio-organic fertilizer and organic-inorganic fertilizer," Soils and Fertilizers Sciences in China, no. 1, pp. 56-59, 2008.

[5] M. Mandalakis, Ö. Gustafsson, T. Alsberg et al., "Contribution of biomass burning to atmospheric polycyclic aromatic hydrocarbons at three european background sites," Environmental Science \& Technology, vol. 39, no. 9, pp. 2976-2982, 2005.

[6] Zh.-Q. Song, "High-value utilization of agricultural and forestry residues resources," Jiangsu Science and Technology Information, no. 12, pp. 1-3, 2008.

[7] M. Kawakami, T. Karato, T. Takenaka, and S. Yokoyama, "Structure analysis of coke, wood charcoal and bamboo charcoal by Raman spectroscopy and their reaction rate with CO2," ISIJ International, vol. 45, no. 7, pp. 1027-1034, 2005.

[8] H. Konishi, K. Ichikawa, and T. Usui, "Effect of residual volatile matter on reduction of iron oxide in semi-charcoal composite pellets," ISIJ International, vol. 50, no. 3, pp. 386-389, 2010.

[9] N. Li, W.-F. Jiang, S.-J. Hao, and Y.-Q. Wang, "Effect of addition agent on the strength of high carbon bearing pellets," Journal of Hebei Polytechnic University, vol. 31, no. 3, pp. 20-24, 2009.

[10] A. Babich, D. Senk, and M. Fernandez, "Charcoal behaviour by its injection into the modern blast furnace," ISIJ International, vol. 50, no. 1, pp. 81-88, 2010.

[11] J. G. Mathieson, T. Norgate, S. Jahanshahi et al., "The potential for charcoal to reduce net greenhouse gas emissions from the Australian steel industry," in Proceedings of the 6th International Congress on the Science and Technology of Ironmaking 2012, ICSTI 2012, pp. 1602-1613, bra, October 2012.

[12] J. Martins et al., "Primary tests of sponge iron production by using green pellets made of iron ores and charcoal mix," Sintering and Pelletizing, vol. 1, pp. 54-56, 1989.

[13] S. Hayashi and Y. Iguchi, "Reaction behavior of wood flour added coal composite iron ore hot briquettes at high temperatures," in Proceedings of the Asia Steel International Conference, pp. 372-377, Fukuoka, Japan, 2006, May 9-11.

[14] M. Nakano, M. Naito, K. Higuchi, and K. Morimoto, "Nonspherical carbon composite agglomerates: Lab-scale manufacture and quality assessment," ISIJ International, vol. 44, no. 12, pp. 2079-2085, 2004.

[15] H. Konishi, T. Usui, and T. Harada, "The Preparation and Reduction Behavior of Charcoal Composite Iron Oxide Pellets," Journal of High Temperature Society, vol. 34, no. 1, pp. 14-19, 2008. 
[16] D.-W. Li, Ch.-Sh. Yue, H.-L. Han, and D.-P. Duan, "Application of straw fiber as the reducing agent in production of metallic pellets," Environmental Engineering, vol. 34, no. 1, pp. 119-112, 2016.

[17] Zh.-L. Liu, J.-L. Wang, Zh.-J. Su, X. Yang, and K. Liu, “Analysis of the measurement on reducing the fuel rate of blast furnace in pingxiang iron and steel co," Journal of Hunan University of Technology, vol. 26, no. 1, pp. 96-100, 2012.

[18] Zh.-G. Ren, Y.-Sh. Zhou, L.-J. Wang, and W.-Zh. Li, "Study on the metallurgical properties of cold-boned carbon-bearing pellets," Sintering and Pelletizing, vol. 21, no. 6, pp. 12-22, 1996.

[19] T. Du and K. Du, "Application-basis study of key technologies in carbon-bearing pellets-iron bath smelting reduction process," Jinshu Xuebao/Acta Metallurgica Sinica, vol. 33, no. 7, pp. 727728, 1997.

[20] J. Pan, D.-Q. Zhu, K.-Ch. Zhang, F.-Ch. Tian, A.-P. He, and X.-F. $\mathrm{Xu}$, "Experimental Study of Improving Green Balls Properties by Modifying Bentonite," in Proceedings of 2005 National Technical Communication Congress of Sintering and Pelletizing, pp. 32-36. 

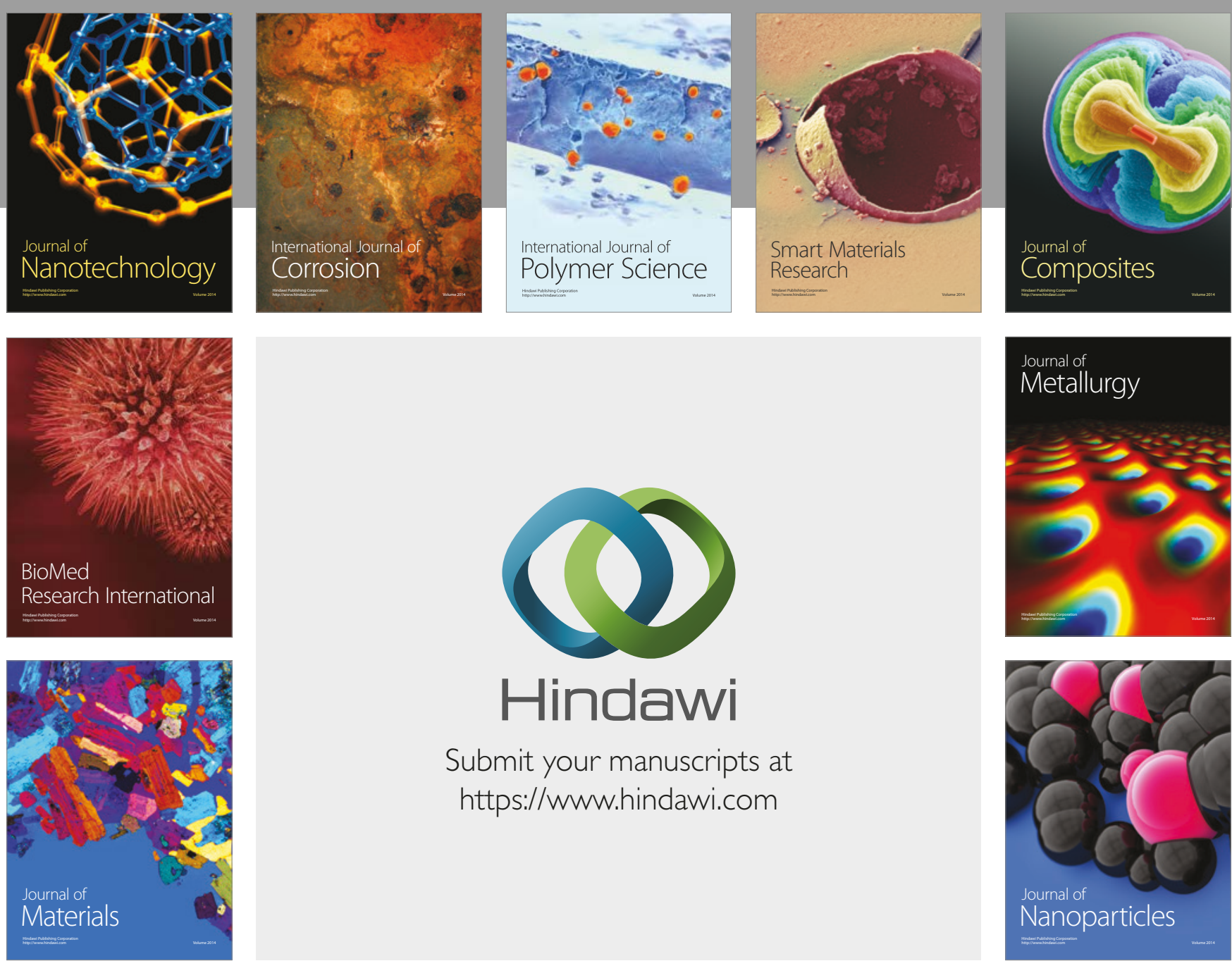

\section{Hindawi}

Submit your manuscripts at

https://www.hindawi.com
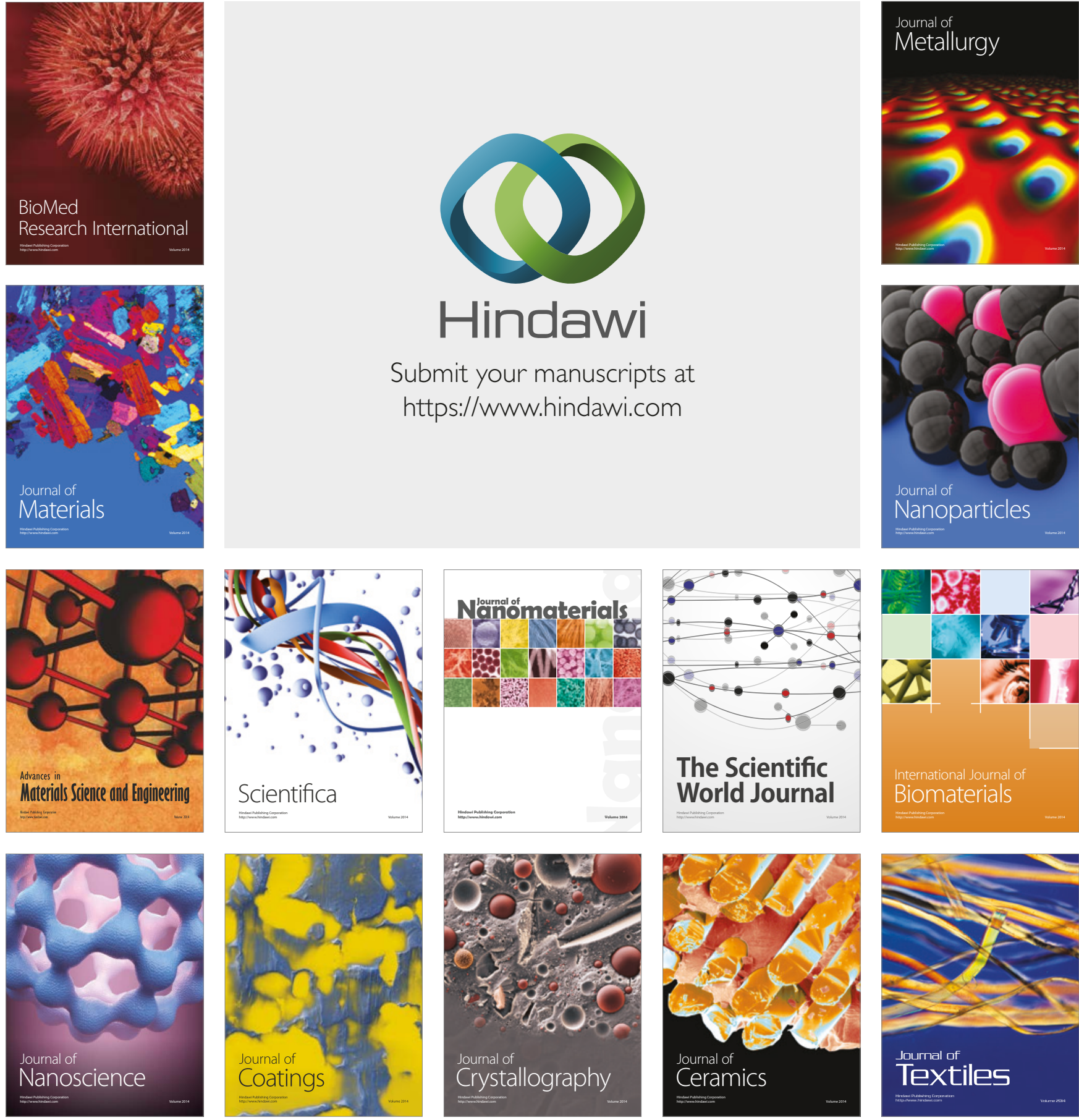

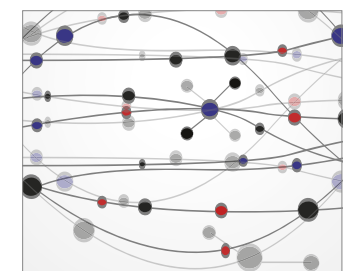

The Scientific World Journal
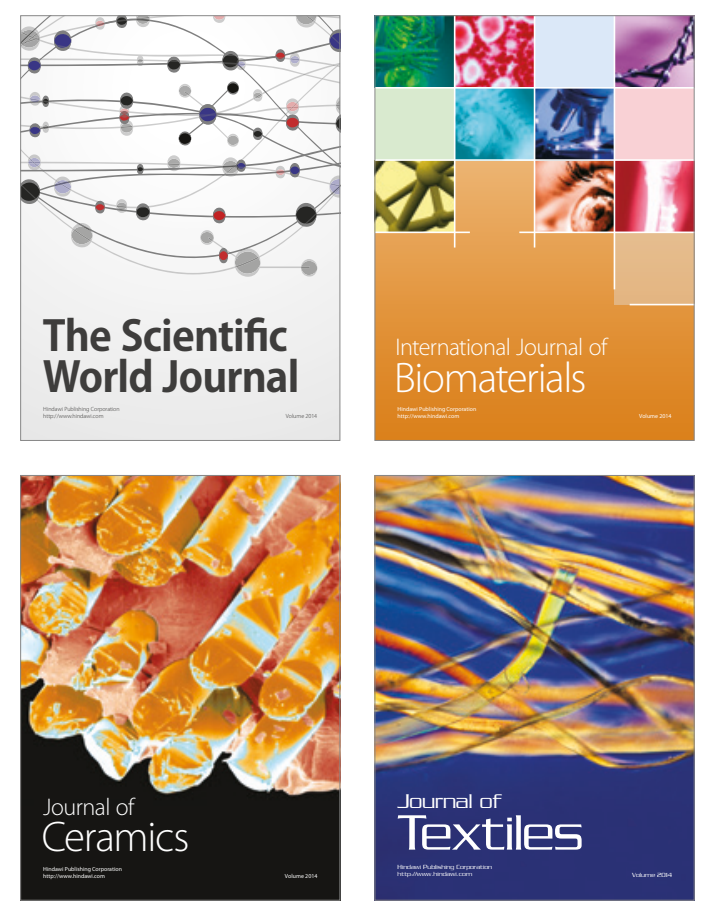